\title{
Communicating Heart Disease: Myth and Magic
}

\author{
Anthony Ferri
}

Mediale Darstellungen und die dadurch konstruierten Mythen über Herzkrankheiten fübren zu einer Dramatisierung der Medizin jenseits ibres grundsätzlichen Kontextes und ibrer Grundlagen. Der vorliegende Beitrag untersucht die Rolle von Mythen in der medienbezogenen Darstellung von Herzkrankheiten. Außer der simplen Verbreitung ungenauer Informationen oder Mythen über Herzkrankbeiten können Medien - unbewusst - dazu beitragen, Herzkrankheiten durch die dramatische Darstellung zu fördern. Die Analyse stellt dar, wie Mythen in der US-amerikanischen Kultur erlebt werden, welche Funktionen und Auswirkungen sie haben. Es wird gezeigt, dass die mediale Darstellung von Herzkrankheiten eher dem Mythos denn der Wissenschaft folgt, was wiederum zu Feblinformationen über die Krankheit auf Seiten der Rezipienten fübrt.

Keywords: Erzählforschung, Gesundheitskommunikation, Herzkrankheiten, Medien, Mythen

Heart disease continues to claim the lives of thousands of men and women in the United States. The American Heart Association AHA claims that heart disease has been the number one killer in the United States every year since 1900, except for 1918 (AHA, 2001, p. 4). In the most recent statistical profile from AHA for the year 1999 (AHA, 2002), cardiovascular diseases (heart attack, stroke, congestive heart failure, congenital heart disease and high blood pressure) accounted for 445,971 male deaths and 512, 904 female deaths, with cancer being second in leading cause of death for both men and women (285, 832 males, 264,006 females). According to AHA data (AHA, 2002b), the coronary event rate for men is highest per 100,000 in Finland (North Korelia, 835) and lowest in China (Beijing, 81). For women, the highest event rate was in the United Kingdom (Glasgow, Scotland, 265) and lowest in Spain (Catalonia, 35).

Media portrayals and the myths they construct about heart disease continue to make concrete and dramatize medical science beyond its fundamental context and foundation. According to the American Heart Association, there is evidence to suggest a relationship between the risk of cardiovascular disease and environmental and psychosocial factors. Factors such as job strain, social isolation and personality traits may impact on a person's cardiovascular health. (AHA, 2003). If the dramatic images about heart disease can produce stress about the disease in the very audiences who are exposed to such images, then such media portrayals are potentially taxing on media audiences. Far more than simply disseminating inaccurate information or myths about heart disease, the media may be, unwittingly, creating an environment encouraging heart disease through its dramatic portrayals.

The importance of the media in developing metaphors and images of the world outside was expressed in the last century by journalist and critic, Walter Lippmann (1965/1922). He suggests that we do not plan our actions according to the objective or real world, but we did react to the "pictures in our heads" of the world outside provided by others and the media (p. 16). These pictures about heart disease in American media have spawned books, diet plans, food labeling, health associations, and even a new lexicon (the cholesterol, good fat, bad fat, heart healthy, etc.). 
The distinction between science and non-scientific interpretation of medicine and health is rooted in the principles of one of the founders of Western medicine, Hippocrates. Hyde (1993) reminds us of this distinction in Hippocratic Law “... for as written in the Hippocratic Law, 'There are in fact two things, science and opinion; the former begets knowledge, the latter ignorance." (p. 202). What is referred to here as "science" will be considered "magic" in this paper, while what is called "opinion" will be designated as "myth."

The heart is, without question, one of the most important parts of the human body. It is a complex pump that brings in deoxygenated blood from the body via the vena cava and then pumps this blood to the lungs through the pulmonary artery. The reoxygenated blood returns, via the pulmonary veins and is eventually pumped via the aorta to all parts of the body. So it is functionally very important.

But the heart is also the source of much of our dramatic culture. The heart is synonymous with love and all that is involved with that aspect of the human condition. The merging of heart and love is also a large part of our language. We "love" this person or we can "love" ice cream with "all our heart" even if our heart does not because of the fat and cholesterol contained in the ice cream. We don't need to understand "myocardial infarction," since we can see some overweight man being "attacked" by heart disease in the form of a "heart attack."

\section{Myth as Experience}

Lakoff and Johnson (1980) maintain that humans guide and interpret their perceptions and behavior in large part through metaphors. The ontological metaphor of the "mind as machine" can be seen in phrases like "I'm a little rusty today" or "my mind isn't operating today." (p. 27). It is common for cardiologists to describe an angioplasty procedure, the use of a catheter with a balloon to open up an occluded artery, as a type of plumbing process in which the "clog" is flushed out of the pipes. The term "heart attack," whose medical term is "myocardial infarction," gives one the impression that the heart is under attack from some outside force. In fact, the heart is not attacked but one or a number of the arteries are occluded or stop flowing to the heart and causing cell damage and potential death.

The process of metaphorical perception can be so persistent and so subtle as to be subliminal to our conscious efforts. Thus, "ontological metaphors ... are so natural and so pervasive in our thought, that they are usually taken as self-evident, direct descriptions of mental phenomena." (p. 28).

Broader and inclusive of metaphors, myths "provide ways of comprehending experience; they give order to our lives ... and just as we often take the metaphors of our culture as truths, so we often take the myths of our own culture as truths." (p. 186). Graeme Turner (1988) contends that the function of myth in society is to help us accept the unexplainable or contradictory.

Lakoff and Johnson (1980) essentially question the assumptions about empiricism developed by John Locke. Locke's theory of knowledge assumed that everything in our mind, or ideas emerge initially from observation of the real world. We use our "reason" to trace our ideas back to their original observations. Lakoff and Johnson (1980) argue that "it can be misleading ... to speak of direct physical experience as though there were some core of immediate experience which we then 'interpret' in terms of our conceptual system." (p. 57). The process of experience, the essence of empiricism, is described as "all experience is cultural through and through, ... we experience our 'world' in such a 
way that our culture is already present in the very experience itself.” (p. 57). John Fiske (1989) claims that "the meanings of health are social and not physical ... health and beauty are equally sociopolitical and are therefore discourses for the exercise of social power" (p. 92).

Lakoff and Johnson share the assumptions of Kant (1952/1781), who argued that some knowledge is a-priori experience of the world - and necessary to knowledge of the world. Reason, Kant argued, provides categories with which we interpret empirical observation. These categories are mental structures like space, time and causation that we use to structure our experiences. Because we cannot experience without organizing what we experience, we have to distinguish between what actually exists (the thing or referent) from what we perceive (our label for the phenomenon).

Our culture tends to offer myths about knowledge according to Lakoff and Johnson. The "myth of objectivism" assumes that some type of pure Lockean empiricism is possible. The "myth of subjectivity" assumes that feelings, aesthetics and moral practices transcend objectivity (p. 188). Lakoff and Johnson offer a different paradigm, "experiential synthesis," in which we constantly negotiate with our environment and other people through reason and imagination (p. 193).

Our knowledge of heart disease is defined by the metaphors and scientific myths in our culture. However, some type of objective reality is assumed by most sciences. Assuming a Lockean perspective about science, it is possible to develop an accurate or veridical view of heart disease if only from those scientists engaged in discovery. Contemporary critics like Lakoff and Fiske suggest that cultural metaphors or sociopolitical assumptions permeate both media interpretation of science and even the scientific process itself.

There is something about heart disease that is almost primeval. Unlike other forms of death from disease, only heart attacks have that sudden look of terror on the face of the man or woman experiencing the attack. This is one part of the picture of heart disease depicted in the mass media and surely in the minds of most Americans. It is a myth, however, since heart attacks and strokes vary from individual to individual. Some victims may think they are having a toothache. Others still may simply feel nauseous or very tired. Still others experience the significant and pronounced pain in the chest and arm. There are certain common characteristics of heart disease and attacks, but they don't always match up with our expectations, our myths about the disease. These common characteristics are part of the reality or the magic of the disease. Because we have such high and negative expectations about the disease, we are eager to remove or at least reduce the incidence of the disease. In fact, the mission of the American Heart Association reflects this:

The American Heart Association is a national voluntary health agency whose mission is to reduce disability and death from cardiovascular diseases and stroke.

(AHA, 2003).

Heart disease is communicated through two basic channels that can be called myth and magic. The myth is the narrative or fantasy about the disease that is disseminated in every communication context or medium and tells us that heart disease is a disease of the heart and attacks the overweight and aged. It is not the objectified reality but we think we know about the disease. It is the "heart attack" and not a "myocardial infarction." Magic is the reality about the disease. It is the science of the heart and the science of the medicine for the heart. It is what the lay public does not know about the disease for the most part. It is referred to as magic to denote a sense of secrecy. Like watching a magician perform, we the audience see the magic but are not privy or perhaps do not care to know 
how the trick was done. Admittedly we are not talking about tricks when it comes to medicine, but it is a magical process.

The importance of myth in health communication was first articulated by Dean Barnlund (1976) referring to a "mystification" in which "meanings, not merely physical symptoms ... prompt people to seek or avoid [health-related] examination, that cause them to withhold or describe their condition ... the entire process ... is invested with symbolism.” (p. 725) Thus, heart disease as myth may instill fear and anxiety and prompting heart patients to seek or avoid testing and examination of their cardiovascular system.

The myth in this process of myth and magic is also grounded in Fisher's narrative paradigm (1984). Fisher claims that we are basically narrative beings or what he calls "homo narrans" with a rationality based in coherent stories and narrative fidelity or stories that ring true and can be tested $(1984$, p. 8$)$. An important feature of the narrative paradigm for this current paper is that the narrative paradigm is "a ground for resolving the dualism of modernism: fact-value, intellect-imagination, reason-emotion and so on." (1984, p. 10). The dualism of myth and magic of heart disease has led to a search for narrative rationality in the mass media.

Kreps and Thornton (1992) advance the use of the narrative paradigm as part of the therapeutic process in health communication. They suggest that health care providers can use narrative to humanize health communication by reducing uncertainty about disease and procedures and managing meanings (pp. 37-39).

Myth and magic of heart disease sometimes clash when they are portrayed in the mass media or in other communication contexts like physician-patient interactions. It has been the myth of heart disease that has led to the development of new areas of science, magic, to aid in the reduction of the disease. Again, this process has been successful in reducing death due to the disease. Yet, many myths continue and cardiologists and organizations, like the American Heart Association, try to inform the public of the magic about heart disease.

There is a continual dynamic relationship between myth and magic through the communication of each. Without the powerful myth of heart disease in the mass media, for example, the development of powerful drugs and new lifestyle habits would have either been delayed in time or perhaps sometimes, not been developed at all. The myth is necessary, to a certain extent, to help the magicians - cardiologists, thoracic surgeons, and cardiovascular scientists - defeat the disease.

Contemporary science and knowledge about heart disease is disseminated to the mass media. News media have their science writers summarize and interview the magicians who have discovered the latest magic (e.g. like a study on baldness and likelihood of having a heart attack). There is also scientific information sent from the magicians to organizations like the American Heart Association at formal meetings like the Scientific Sessions held in Dallas, Texas. These organizations also communicate with the media. The mass media communicate this "information" to the general public or to the "individuals." The end product here is myth, which is in itself changed over time with some aspects of the magic enlarged or exaggerated, etc. These myths may themselves be the source of other myths. Myths are sent back to the media and to individuals.

The cultural expectations of people in the U.S., and the media images portrayed, are likely unique in terms of health. In a study of health care and treatment in Britain, the United States, France and the former West Germany, Lynn Payer (1988) found, for example, that U.S. doctors performed six times as many cardiac bypass operations per capita as compared to British doctors. Clearly, values, expectations and priorities vary from country and culture. 


\section{Myth as Reification}

A process of "reification" occurs when magic becomes myth. Abstract concepts, like heart disease, can be referenced and interpreted even by non-experts. Such "interpretation," however, does not result in expert or even necessarily accurate understanding. The magicians, the physicians and scientists working in this area, live in both the magic and mythic fields. Thus, there is an overlap between them and individuals, media and organizations. Medical practitioners work with other practitioners, but interact and communicate with non-medical individuals, the media and organizations like the American Heart Association. What was once medical science now becomes something tangible, visible, or thematic. The myth becomes the referent or what is perceived as objective reality by the media audience. Heart disease myth is the result of accumulated culturally constructed metaphors in which details of the full scientific account are left out. It is science simplified for mass consumption.

In a wide-ranging review of critical theory and discourse research, Gwyn (2002) examines how health and illness are communicated in our language. Gwyn describes the reification process in the following:

The attribution to illness itself of an 'otherness' can be paralleled in modern Western culture by a dissociation on the patient's part that is often expressed, or hinted at, in that particular person's use of language. This pursues the Western cultural distinction between mind and body prevalent since Descartes in the seventeenth century. The term used for conceiving the body as 'other' to the self is reification. (p. 23).

Only professionals in the field, like cardiologists and thoracic surgeons, maintain a currency on the scientific or magic. Most Americans receive scattered bits of scientific, magical, information in the media somewhat infrequently and in a highly selective manner. This is not knowledge of heart disease; it is not the magic about heart disease. It is the news about heart disease. It is what Bernard Roshco called a "timely acquaintance with" events and information, not knowledge (1975, p. 7). It is heart myth.

\section{Magic Known Only to Magicians}

The magic about heart disease is the scientific knowledge about the disease and the collective medical and clinical resources, including surgical techniques, drugs, diet, and exercise. For the most part, only those people connected to the science and medicine are continuously and fully interested in the magic. Because of their livelihood and personal interests, they are privy to and understand what magic there is and its limits. Essentially, what they do is like magic. They can't cure heart disease, but they can successfully transplant hearts, bypass blocked arteries, and extend lives. Though there are books that will describe such operations in simple language (see, for example, Yalof, 1983), most non-magicians do not read such material unless they have recently discovered they have heart disease or a loved one has.

The magic about the somewhat common practice of coronary bypass surgery is very much a magical experience. What most people really know about this procedure is as much as what most people know about how a jumbo jet gets off the ground and stays off the ground. They know that something to do with physics, air streams, and jet propulsion are involved. But when you really think about it, flight is magic. The same can be said for heart surgery. How do they, the surgeons, graft those tiny pencil lead thin vein grafts to the arteries? For a surgeon who does this several times each month, it is 
both familiar and personal experience. For the rest of us, it is magic. We know that magicians use deception and apparatus to deflect us away from their magical stage tricks. Heart magicians don't need to do this because we're not looking. We prefer only to see the results, a renewed and revived body with an extended life.

Only magicians know the magic, while the myth is more widely known. The myth is the highly selected drama about heart disease. It is what is seen in the movies and other media. It is the "heart attack," though in reality, in magic, the heart is not attacked as such. The coronary arteries are clogged over time by low-density lipoproteins (LDL's). It is an evolutionary process and certainly not an attack. The clogged or occluded arteries then reduce blood flow to the heart and if the artery is complete occluded, there is a myocardial infarction of the heart (damage to the heart muscle due to the blockage of the artery).

\section{Myth as Drama}

The story about heart disease is highly selective. Drama, after all, focuses on elements of conflict and character and uses only those elements to advance and interpret each. Moment-by-moment details of everyday life are excluded. What follows are a few examples of the portrayal of medicine and heart disease in film and television. Future research on the portrayals of science versus fiction in portrayals of diseases, like cardiovascular diseases, while desirable, could be a logical outcome of this current essay.

The essence of drama is to isolate people in limited time and space and articulate themes through selective use of action and dialogue. The everyday and mundane are usually left out. Drama, by nature, exaggerates some details over others. Complex processes, like heart disease, cannot be covered in dramatic form in any other way than from the direst stage, the heart attack. Movies, news, and episodic television are dramatic representations of the world. The myth of heart disease is especially suited for the mass media because of the dramatic element of the most acute stage of heart disease - the attack.

In a summary of the research on perceived reality and media, Potter points to the generalization that real-life experience tends to reduce a person's likelihood of accepting the media portrayals as real (Potter, 1988). Even with the thousands of heart bypasses every year, most people do not have heart attacks or surgery. Their experience is limited, thus, they are more apt to rely on the media portrayal. These portrayals add to the myth of heart disease.

In a content analysis of the treatment of illness on television network programming, it was found that "while severe trauma, heart problems, and mental illness garnered much of TV's interest, the focus was almost exclusively on acute stages of those problems." (Turow, 1985, p. 99). Little attention was given to the long-term aspects of the disease, both physical and psychological. Diem, Lantos \& Tulsky (1996) found that CPR (cardiopulmonary resuscitation) as portrayed in U.S. television dramas like $E R$ and Chicago Hope is given mostly to children and young adults with most of these patients recovering. In fact, CPR is more likely to be used on elderly persons having heart attacks and only a minority being saved. The myth of heart disease, constructed by entertainment media, is one of success and youth. Because television shows like $E R$ have large audiences, the myth can disseminate widely.

In addition to popular television series, widely popular movies can extend the myth about heart disease. The movie The Godfather (1972) was a film of great popular- 
ity, ${ }^{1}$ and one that is described here because of the central character, actor Marlon Brando's Don Corleone. Also, the film continues to play on television and is rented in video stores. It is a heart attack that kills the powerful godfather. This is one of the messages that is clearly shown in the movies. This is a powerful disease. The don did survive a dramatic scene in which several, close range shots were fired at him. But in the end, Don Corleone is struck down by a heart attack in his garden while playing with his grandchild. It is also interesting to note that Brando's portrayal of a heart attack has him fall to the ground in dramatic fashion. However, no one says that he dies of a heart attack. The audience must interpret the schema of the Don's sweating, panting, gasping for air, and fall as collectively demonstrating the attack.

What you do not see in the movies are many examples of women and heart disease. The next film is described here because it does portray a woman with heart disease even though the film is from the 1980s. Barbara Hershey plays a wealthy attorney and longtime friend to Bette Midler who plays a famous actress in the movie Beaches (1988). Hearshey's character suffers from viral cardio biopothy, in which the heart muscle eventually deteriorates. The disease leaves her with symptoms of shortness of breath, fatigue, and dizziness. Rather than experiencing the dramatic myocardial infarction, this movie character, a female, slowly dies of a heart ailment.

Drama as media content is designed to entertain in the final analysis. Commercial televison, radio, magazines and newspapers must attract and maintain audience through such drama. As Nancy Signorielli (1998) suggests:

Entertainment programming is storytelling, and any health issue that makes its way into an entertainment program must have a good storytelling component. Portrayals of health must fit with the story line and be compatible with the characterizations. Such portrayals can be incorporated in entertainment progamming only if script writers and producers are aware of and take an interest in them. (p. 179).

Thus, the depiction of heart disease in entertainment media must be entertaining, regardless of fictional or non-fictional accounts. Capturing audiences for advertisers requires attention to what moves an audience rather than what informs an audience.

\section{Myth Manufactures Magic}

The investigation and production of new medicines, surgical procedures, and drugs require great amounts of money. Heart disease and the magic for heart disease have grown up during the rise of technologies. The greatest rise of death rates due to heart disease in the United States emerged between World War I and the mid-1970s (Kushi and Jack, 1985, pp. 9-12). It is during this period that we have seen the rise of transportation technology, communication technology, and health technology. The image of heart disease as a powerful killer is most widely seen in the 1960s and 1970s. What is most important is that there is no cure for heart disease and during that period there was no clear escape from the grips of the heart disease monster - until December 3, 1967. On that date Christiaan Barnard did the first heart transplant in South Africa. The antecedent technologies that allowed for the development of this magic included the heart-lung machine, devel-

1 The film's worldwide gross was $\$ 268,500.00$ (USD). Source: The Numbers: Box office data, movie stars, idle speculation. Retrieved March 29, 2003. http://www.the-numbers.com/movies/1972/0GDFT.html 
oped by Dr. John Gibbon in 1953. This allowed surgeons to operate on and around the heart while it is stopped. The heart-lung machine takes over the function of the heart and lungs by adding oxygen to the blood and returning it to all parts of the body. By the 1960 s the first coronary bypasses were performed. Today, there are about 500,000 bypasses performed each year. In 1984, one percent of the gross national product in the United States was spent on coronary artery bypass operations alone (Kwiterovich, 1993, p. 5). This collection of magical technology has been developed in a relatively short time. This rapid development is the result of the fearful audience viewing and reacting to the myth by giving money to further research.

Since the time of the first heart transplant to now, there has been a significant decline in death rates due to cardiovascular disease. It has been during this period that there has been a growth in media campaign messages about heart disease with the myth about the disease in the mass media. This mixture of myth and magic, also magic grounded in myth, has lead to the growth in private and public dollars generated for heart magic drugs, surgical techniques, and heart healthy programs.

The myth of the powerful disease attacking both old and out-of-shape American males is the consistent symbolic message portrayed in the popular media. Redd Foxx as the out-of-shape and aging Fred Sanford was the most likely to die by a heart attack according to his fake attacks on the show Sanford and Son. You rarely see young, energetic, and thin people having heart attacks in movies or television. If you did, the myth would not allow most of America to feel threatened by the disease. Since many if not most Americans are either overweight or feel overweight, they are under threat of heart attack. Thin is a safety shield against the disease, at least according to the media portrayals - or the absence of thin models for heart disease. This single criterion is a myth. Being thin by itself is not the solution or prevention against heart disease. It is typical of the simple solutions to life's more complex problems. The magic of heart disease is open to all sizes, shapes, and both sexes.

Without a good story, there is little motivation for people to continue their efforts to slay the monster of heart disease. Of course, the reality of death or disability due to cardiovascular diseases will certainly motivate people to produce drugs and surgical techniques. Still, the significant change in our overall view of the disease and the ability for researchers and medical practitioners to convince public and private groups to spend the dollars on the disease is made all the easier when there is a dramatic story to tell.

\section{Myth “De-Scientizes” Medical Research}

Science, as a process, is piecemeal in its outcomes. The notion of a "line of research" is concerned with an ongoing study of some phenomenon until the totality of that phenomenon is fully demonstrated or known. The peer evaluation process in science also restricts the totality of what is known about some phenomenon through the blind reviewed papers that eke out slowly. Expert readers and reviewers of manuscripts conduct this process on a part-time basis. They are themselves conducting their own research, teaching and are involved in other professional responsibilities. The academic research process is based on accuracy and generalizability. The pace of the process of the development of research knowledge is regulated by peer review, publication and professional conferences.

An audience wants the story now and in a definable product as disseminated by health news writers regulates scientific information. Walter Lippmann (1922) spoke of 
this years ago when he suggested that news and truth are two different processes with news being some part of the truth. Thus, media stories are crafted based on the bits and pieces of information found from research journals. The theoretical and research context from which the research data is garnered is absent from the media version. Research on cardiovascular diseases, for example, is interpreted by media without the qualifiers of whether the studies were experimental or correlational in nature. The media are only interested in the results and not how the scientists came up with the results or their generalizability.

Such misuse of science leads to everyday problems. While some studies suggest a link between moderate alcohol consumption (1 to 2 ounces per day) and elevation of highdensity lipoproteins or "good fats" (Charash, 1991, p. 226), some people may fail to follow such moderation and drink too much, thus adding to the likelihood of causing liver damage. Myth requires no regimen.

\section{Consequences of the Myth}

Myth may well reduce or destroy the magic it helped create. The myth is grounded in magic and new myths may appear. The new myth about heart disease in the near future may be that it is not the all-powerful disease. Once the monster is out of sight it may be just a matter of time before our good habits cease. We exercise less and eat less heart healthy foods. We may come to believe that the new developments in genetic engineering may excuse us from taking responsibility for the health of our bodies. The result could thus be a new wave of deaths due to heart disease. Our myths about heart disease communicate our collective fears and hopes for and about the disease. Communicating heart disease in our society can either limit or advance our understanding and our ability to limit the extent of the disease in our generation.

Mythic heart disease regenerates stereotypes. Perhaps the biggest myth about heart disease is that it is a man's disease. Women are equal victims to the disease but unequal in terms of prevention or reduction. Overall, women are not treated equally in the media or in doctors' offices as candidates for the disease. Much recent literature has come out testifying to the fact heart disease kills women. However, the myth has been developed and promoted by men in the media.

Karen Lurie makes the point that "heart disease isn't 'sexy"” (2002):

The cover of ... (a) Time magazine features a naked, airbrushed, very thin woman with blond hair, shown from the waist up, standing sideways, covering her breasts with one arm while the other is awkwardly bent upward ... Is this why we'll never see a Lifetime movie about a woman with heart disease? ... Because the struggle with heart disease doesn't seem noble or feminine enough? Because it can't be trivialized and reduced to sexual terms? Because it doesn't require actresses to be filmed examining their naked selves in the mirror?

In a recent $\mathrm{BBC}$ story, the British Heart Foundation BHF is reported to have claimed that more must be done to alert women to the dangers of heart disease, which killed over 54,000 women in 2001 - more than four times the number killed by breast cancer. The lack of portrayals of women with heart disease in media exacerbates this problem:

The BHF says women must look after their heart health, and calls on the press and

TV dramas to help by showing heart disease affects women as well as men. (BBC, 2003).

One clear consequence of the current myth of heart disease as powerful is that the job is not yet complete. We need more research and more programs to combat the disease. If 
the myth changes and heart disease is powerless or easily controllable, then the job is complete. We, as a society, fail to nourish our knowledge and other resources used to accomplish the reduction of the mythical monster. The duality of myth and magic is essential to our goals of reducing heart disease death and disability.

Unfortunately, this duality comes with a price. The myth about heart disease is a narrow vision. For instance, we have failed to treat women with the same degree and dedication as men in terms of heart disease and medicine. While the tide may have turned recently with a new interest in women in heart disease (by the American Heart Association, for instance), the current myth about women and heart disease can be deadly. While there has been research on sex differences showing a bias favoring men in access to more invasive heart surgery after catheterization, more recent investigations suggest that the level of disease and how the disease is exhibited differs between men and women (Ghali, W. A., Faris, P. D., Galbraith, P.D., et al., 2002). Still, heart disease has been viewed as a "man's" disease, it is inevitable that women may be treated with a male-dominated magic. Women experience heart disease in equal numbers to men after women reach menopause. However, the myth about heart disease continues to emphasize it as an old fat man's disease. The consequence is that many women may receive substandard treatment, and at worst, many will die from the disease without being given a fighting chance.

Science does not advance its own cause. Our collective fears and hopes as outlined in our myths help to advance the level of science or magic. Cultural differences among nations also define the level of medical technology they desire and develop. Science, including heart science, is generated by myths of interest and intrigue.

The myth of heart disease is powerful. The simple fact is that for many of us one of our worst nightmares is having excruciating chest pain and being felled by an attack to our heart. It is so powerful a myth that we have changed our lifestyles in order to avoid the pain. But the myth has been manufactured and created the desire and belief in magic bullet. We can eat oatmeal or salmon or salmon oil tablets. We have tried to destroy the myth with other myths mixed with a little magic. While many people now exercise and eat more heart healthy, they may still smoke or avoid stress management. And for all our emphasis on heart healthy behaviors it is still very difficult to avoid fats, cholesterol, and stress. Until we have universal packaging of all foods, we are still apt to find some potato chips say "cholesterol free." We might as well just put "fat free" and "cholesterol free" on cigarette packs. In the U.S., Americans are losing the "battle of the bulge" and weight gain is worsening among youth. Recently the American Obesity Association gave a grim report:

The percentage of children and adolescents who are overweight and obese is now higher than ever before. Poor dietary habits and inactivity are reported to contribute to the increase of obesity in youth. Today's youth are considered the most inactive generation in history caused in part by reductions in school physical education programs and unavailable or unsafe community recreational facilities. In the U.S., only the state of Illinois requires daily physical education for students in grades $\mathrm{K}$ to 12 . (2002, p. 1)

It is difficult to say what factors have lead to such physical inactivity among youth, but it is clear that in addition to lack of school-based exercise, the youth of America are electronically living their lives through television screens and computer monitors. These youth are entertained, informed and acculturated through television and cable programs and electronic games about values and their future. These same media often offer the quick fix to life's problems. This is the environment nourished by myth, not magic. 
Could our youth be basing their future health on the myths generated by the media and their mythic translations of medical magic?

The media portrayal of heart disease is more myth than science. If such myths are based on fear, then the conditions that can foster stress and perhaps heart disease have been created. For example, a "mitral valve prolapse," an abnormality in the mitral valve of the heart is a complex condition and has been oversimplified through myth and fear as suggested by Charash (1991):

There are many fears about this condition. Most are totally groundless. Reports of strokes, arrhythmias, and sudden death among people with mitral valve prolapse have contributed to the exaggerated public concern. These reports must be put into perspective. Mitral valve prolapse is not a simple, single condition. There are many different degrees of prolapse, some of which are more serious than others. But the overwhelming majority of people with MVP are totally healthy. (p. 197)

The heart has been a symbol of love and other gifts of the human spirit such as extension of life through heart transplant. Media portrayals of the heart, whether in fiction or news, can aid in the extension of the lives of human hearts through a more magical or scientific interpretation of heart disease. It is a problem of balancing myth and magic in the mix of media entertainment and information.

\section{References}

American Heart Association (2003). Heart disease and stress. Retrieved March 30, 2003. http://www.americanheart.org/presenter.jhtml?identifier $=4750$

American Heart Association (2003). Mission. Retrieved March 30, 2003. http://www.american heart.org/presenter.jhtml?identifier $=10858$

American Heart Association (2002). Heart and stroke statistical update. Retrieved November 25, 2002. http://www.americanheart.org/statistics/

American Heart Association (2002). International cardiovascular disease statistics. Retrieved November 25, 2002. http://www.americanheart.org/statistics

American Heart Association (2001). Heart and stroke statistical update: http://www.american heart.org/statistics $\backslash$

American Obesity Association (2002). Obesity in youth. Retrieved, November 27, 2002. http://www.obesity.org/subs/fastfacts/obesity_youth.shtml

Barnlund, D. (1976). The mystification of meaning: Doctor-patient encounters. Journal of Medical Education, 51, $716-725$.

BBC News. (2003). Women 'unaware of heart risk.' Retrieved March 30, 2003. http://news.bbc. co.uk/2/hi/health/2735677.stm

Charash, B. D. (1991). Heart myths. New York: Penguin Books.

Diem, S. J., Lantos, J.D., \& Tulsky, J. A. (1996). Cardiopulmonary resuscitation on television: Miracles and misinformation. New England Journal of Medicine, 334, 1578 - 1582.

Fisher, W. R. (1984). Narration as a human communication paradigm: The case of public moral argument. Communication Monographs, 51, 1-22.

Fiske, J. (1989). Understanding popular culture. Boston: Unwin Hyman, Inc.

Ghali, W. A., Faris, P. D., Galbraith, P.D., Norris, C. M. Curtis, M. J., Saunders, L. D., Dzavik, V., Mitchell, L. B., \& Knudtson, M. L. (2002). Sex differences in access to coronary revascularization after cardiac catheterization: Importance of detailed clinical data. Annals of Internal Medicine, $136,723-732$.

Gwyn, R. (2002). Communicating health and illness. London: Sage Publications, Ltd.

Hyde, M. J. (1993). Medicine, rhetoric, and euthanasia: A case study in the workings of a postmodern discourse Quarterly Journal of Speech, 79, 201 - 224. 
Kant, I. (1952/1781). The critique of judgement. J. C. Meredith, Trans. Oxford: Clarendon Press. Kreps, G. L. \& Thornton, B. C. (1992). Health communication: theory and practice. $2^{\text {nd }}$ ed. Prospect Heights, IL: Waveland Press.

Kushi, M. \& Jack, A. (1985). Diet for a strong heart. New York: St. Martin's Press.

Kwiterovich, Jr., P. O. (1993). The Johns Hopkins complete guide for preventing and reversing heart disease. Rocklin, CA: Prima Publishing.

Lakoff, G. \& Johnson, M. (1980). Metaphors we live by. Chicago: University of Chicago Press.

Lippmann, W. (1965/1922). Public opinion. New York: The Free Press.

Locke, J. (1990/1690). Drafts for the essay concerning human understanding, and other philosophical writings. P. H. Nidditch \& G. A. J. Rogers (eds.). Oxford: Clarendon Press.

Lurie, K. (2002). Making cancer sexy. PopPolitics.Com. Retrieved, March 30, 2003. http://www.poppolitics.com/articles/2002-02-22-breastcancer.shtml

Payer, L. (1988). Medicine and culture: Varieties of treatment in the United States, England, West Germany, and France. New York:Penguin Books.

Potter, W. J. (1988). Perceived reality in television effects research. Journal of Broadcasting \& Electronic Media, 32, 77 - 102.

Roshco, B. (1975). Newsmaking. Chicago: University of Chicago Press.

Signorielli, N. (1998). Health images on television. In L. D. Jackson \& B. K. Duffy (Eds.), Health communication research: A guide to developments and directions (pp. $163-179)$. Westport, CT: Greenwood Press.

Turner, G. (1988). Film as social practice. New York: Routledge.

Turow, J. (1985). Hospital and healthcare executives on TV: image problems for the profession. Hospitals and health services administration, 30(6), 96-105.

Yalof, I. L. (1983). Open heart surgery: a guidebook for patients and families. New York: Random 